\title{
Influence of Hydrogenation on Residual Stresses of Pipeline Steel Welded Joints
}

\author{
Alexandre Magno de Souza Sant'Anna ${ }^{a, b}$, Ivan Napoleão Bastos ${ }^{c}$, João Marcos Alcoforado Rebellod,
}

\author{
Maria P. Cindra Fonseca ${ }^{a}$
}

\begin{abstract}
a Programa Francisco Eduardo Mourão Saboya de Pós-Graduação em Engenharia Mecânica - PGMEC, Department of Mechanical Engineering, Universidade Federal Fluminense - UFF, Niterói, RJ, Brazil

${ }^{b}$ UnED Itaguaí, Centro Federal de Educação Tecnológica Celso Suckow da Fonseca - CEFET, Itaguaí, RJ, Brazil

c Instituto Politécnico do Estado do Rio de Janeiro - IPRJ, Universidade do Estado do Rio de Janeiro UERJ, Nova Friburgo, RJ, Brazil

d Programa de Engenharia Metalúrgica e de Materiais - PEMM, Instituto Alberto Luiz Coimbra de Pós-Graduação e Pesquisa em Engenharia - COPPE, Universidade Federal do Rio de Janeiro - UFRJ, Rio de Janeiro - RJ, Brazil
\end{abstract}

Received: January 19, 2016; Revised: June 12, 2016; Accepted: July 28, 2016

\begin{abstract}
Hydrogen embrittlement is a phenomenon that affects the performance of steel used for oil and gas pipelines. This paper presents a study of the effect of hydrogenation on the residual stresses of an API 5L X65 steel pipe. Residual stresses were analyzed by X-ray diffraction technique using the $\sin ^{2} \Psi$ method. The hydrogenation of base metal and welded joint specimens was performed by electrochemical tests in a simulated soil solution NS4. Results show that the hydrogenation led to significant changes in residual stress configuration and in the mechanical properties of steel. The hydrogenation increased the magnitude of the longitudinal residual stress of base metal and fusion zone, without changing the tensile/compressive nature. On the other hand, the hydrogenation increased the intensity of the tangential stress of base metal, and changed from compressive to tensile the residual stress of the fusion zone. The microstructural characterization by optical and scanning electron microscopy was used to complement this study.
\end{abstract}

Keywords: Pipeline steel, hydrogenation, residual stresses, mechanical properties

\section{Introduction}

High-strength low-alloy (HSLA) steels are widely used in the production of pipes for the oil and gas industry due to their mechanical properties of high strength, good toughness, and excellent weldability ${ }^{1,2}$. Moreover, the electric resistance welding (ERW) manufacturing process of API 5L X65 steel pipes led to an increase in mechanical strength and toughness of the weld region, even in conditions of low temperature and in the presence of $\mathrm{H}_{2} \mathrm{~S}$ gas $^{3}$. However, ERW requires a high control level to minimize the presence of non-metallic inclusions and temperature gradient in the weld. The nonhomogeneous distribution of inclusions or segregations in the weld may leave the material susceptible to hydrogeninduced cracking, especially in pipes used for transporting hydrocarbons at low temperature ${ }^{4}$. The welding temperature gradient is the principal cause of spatio-temporal changes in the microstructure, which produces non-uniformly distributed plastic deformations and, consequently, high magnitude residual stresses. The nature of residual stresses generated during the pipe manufacturing process can cause a growth in the diffusion flux and hydrogen concentration into the crystal lattice, contributing to the embrittlement process of steel ${ }^{5,6}$.
The failure of steel pipes used in the oil industry is mainly caused by hydrogen effects or stress corrosion cracking. Hydrogen damage occurs because the inner walls of the steel pipes can be in permanent contact with hydrogen sulfide gas generated during the petroleum oil process. This contact of $\mathrm{H}_{2} \mathrm{~S}$ gas with the inner walls of the steel tube gives rise to an electrochemical reaction that simultaneously promotes hydrogen ion reduction. The monatomic hydrogen generated during the electrochemical reaction is initially adsorbed on the surface pipe; and subsequently absorbed by the crystalline structure of steel via diffusion. During the diffusion process, the monatomic hydrogen can be trapped at grain boundaries, precipitations and dislocations ${ }^{7,8}$. Since the hydrogen-material interactions are very complex, several theories have been proposed to explain hydrogen embrittlement (HE) phenomenon. Several authors report that the two most established micro-mechanical models of hydrogen embrittlement are: Hydrogen Enhanced Local Plasticity $\left(\text { HELP) }{ }^{9} \text { and Hydrogen-Induced Decohesion (HEDE) }\right)^{10}$. The HELP mechanism is characterized by a local softening effect due to increased mobility of dislocations, inducing locally reduced strength. However, the HEDE mechanism considers the hypothesis that local enrichment of interstitial 
hydrogen in the atomic lattice lowers the cohesive strength and consequently the fracture energy ${ }^{11}$.

This paper presents a study of the effect of hydrogenation on the residual stresses and mechanical behavior of an API 5L X65 steel, in the as-received and welded by ERW process conditions. The synthetic solution NS4 mimics the soil corrosivity used as a hydrogen source to metallic specimens under cathodic polarization.

\section{Materials and Experimental Methods}

\subsection{Materials}

The studied material was obtained from an API 5L X65 steel pipe with $168.3 \mathrm{~mm}$ diameter and $9.5 \mathrm{~mm}$ wall thickness, manufactured by longitudinal ERW process. The chemical composition and the following mechanical properties of steel: yield strength $\left(\sigma_{\mathrm{YS}}\right)$, ultimate tensile strength $\left(\sigma_{\mathrm{UTS}}\right)$ and elongation $(\varepsilon)$ specified by the API 5L Standard ${ }^{12}$ are shown in Tables 1 and 2, respectively.

In order to study the effect of hydrogenation in residual stresses and mechanical properties of welded joints, eight sets of round tensile specimens and six sets of subsized 10 x 7.5 x $55 \mathrm{~mm}$ Charpy V-notch (CVN) specimens were extracted from the longitudinal and transversal directions of the pipe body (Figure 1), as suggested by API 5L standard.

Specimens were manufactured by machining in accordance with ASTM A370 - 14 ${ }^{13}$, from the base metal (BM) and the fusion zone (FZ). Figure 2 presents a detailed description of all conditions studied in this work. At least three tests were performed for each mechanical result. The processing routes up to the test are indicated by the numbers from 1 to 4 .

Charpy impact tests used specimens in the following conditions: 1) as-received (AR), 2) hydrogenation (H) and 3) stress relief heat treatment with hydrogenation (HT-H), at room temperature. Tensile tests were performed with round specimens in the following conditions: 1) as received (AR), 2) hydrogenation $(\mathrm{H}), 3$ ) stress relief heat treatment with hydrogenation (HT-H), and 4) stress relief heat treatment and pre-straining with hydrogenation (HT-PS-H), at room temperature.

\subsection{Electrochemical tests}

The hydrogenation of specimens was made by electrochemical method, which was performed using the aqueous synthetic soil solution, called NS4 ${ }^{14}$. This solution is commonly used to study the effect of hydrogen on stress corrosion cracking and corrosion fatigue of buried pipes because it has a nearly neutral $\mathrm{pH}$ and contains the main chemicals present in soils ${ }^{15}$. A cathodic potential was applied to produce the electrochemical conditions necessary for the production of monatomic hydrogen.

The cathodic potential for hydrogenation was controlled by using a potentiostat (Onmimetra model 39), and an electrochemical cell with three electrodes: the working electrode (API 5L X65 steel), a counter-electrode (platinum foil), and a saturated calomel electrode reference (SCE). The chemical composition of NS4 (expressed in $\mathrm{g} / \mathrm{L}$ ) is $0.122 \mathrm{KCl}$, $0.483 \mathrm{NaHCO}_{3}, 0.181 \mathrm{CaCl}_{2} .2 \mathrm{H}_{2} \mathrm{O}$ and $0.131 \mathrm{MgSO}_{4} \cdot 7 \mathrm{H}_{2} \mathrm{O}$. The NS4 solution was deaerated with $\mathrm{N}_{2}$ bubbling. The corrosion potential $\left(-0.75 \mathrm{~V}_{\text {sce }}\right.$ ) of steel was obtained after the time of $43.2 \mathrm{ks}$ at open circuit potential under deaerated conditions. A cathodic potential $\left(-1.45 \mathrm{~V}_{\text {sce }}\right)$ was applied to the specimens to allow the evolution of hydrogen ${ }^{14}$, which corresponds to approximately $0.7 \mathrm{~V}$ below the corrosion potential of steel ${ }^{16}$. The exposure time was determined by taking into account the hydrogen concentration ratio $(\mathrm{C}(\mathrm{x}, \mathrm{t}) /$ $\mathrm{C}_{0}$ ) evaluated by solving Fick's Second Law (Eq. 1) with the specific experimental initial and boundary conditions. In the present work, an in-house computational tool written in the SCILAB 5.3 language (INRIA-ENPC) was used. Hydrogen concentration was simulated as a function of sample thickness for a given hydrogen surface concentration and diffusion coefficient. In the simulations, the diffusion coefficient of the hydrogen of steel was considered as $7.93 \times 10^{-11} \mathrm{~m}^{2} / \mathrm{s}$ as found by Olden et al. for the same material ${ }^{11}$, and using the approximation ${ }^{17}$ expressed by Equation (1).

$$
\frac{\mathrm{c}(\mathrm{x}, \mathrm{t})}{\mathrm{C}_{0}}=1-\frac{4}{\pi} \sum_{\mathrm{np}_{\mathrm{p}}=0}^{4} \frac{(-1)^{\mathrm{n}_{\mathrm{p}}}}{2 \mathrm{n}_{\mathrm{p}}+1} \exp \left[-\left(2 \mathrm{n}_{\mathrm{p}}+1\right)^{2} \cdot \frac{\pi^{2}}{4} \cdot \frac{\mathrm{Dt}}{\mathrm{L}^{2}}\right] \cdot \cos \left[\left(\frac{2 \mathrm{n}_{\mathrm{p}}+1}{2}\right) \cdot \pi \cdot \frac{\mathrm{x}}{\mathrm{L}}\right](1)
$$

where $\mathrm{D}$ is the diffusivity, $\mathrm{x}$ is the distance, $\mathrm{C}_{0}$ is the concentration on the metal surface, $\mathrm{L}$ is the specimen thickness, $t$ is hydrogenation time and $n_{p}$ is the number of terms in the power series. The term c expresses the concentration at position $\mathrm{x}$ and time $\mathrm{t}$.

The exposure times for the hydrogenation of each round tensile test specimen $(4.0 \mathrm{~mm}$ diameter) and Charpy impact specimen (7.5 $\mathrm{mm}$ thickness) were 40 and 126 hours, respectively. These exposures correspond to the time in which the simulated hydrogen concentration ratio in the center of the specimen attains $90 \%$ of the surface concentration. The initial hydrogen concentration in the steel was assumed as null. The hydrogen concentration was estimated according to Fick's second law (Eq. 1).

Table 1: Chemical composition (wt. \%) of API 5L X65 analyzed steel.

\begin{tabular}{lcccccccccccc}
\hline $\mathrm{C}$ & $\mathrm{Si}$ & $\mathrm{Mn}$ & $\mathrm{P}$ & $\mathrm{S}$ & $\mathrm{Cr}$ & $\mathrm{Ni}$ & $\mathrm{Mo}$ & $\mathrm{V}$ & $\mathrm{Ti}$ & $\mathrm{Nb}$ & $\mathrm{Al}$ \\
\hline 0.128 & 0.247 & 1.35 & 0.011 & 0.0035 & 0.022 & 0.016 & 0.0024 & 0.003 & 0.0029 & 0.051 & 0.033 \\
\hline
\end{tabular}


Table 2: Mechanical properties of API 5L X65 analyzed steel.

\begin{tabular}{lcc}
\hline$\sigma_{\mathrm{YS}}(\mathrm{MPa})$ & $\sigma_{\mathrm{UTS}}(\mathrm{MPa})$ & $\varepsilon(\%)$ \\
\hline 476 & 575 & 18 \\
\hline
\end{tabular}

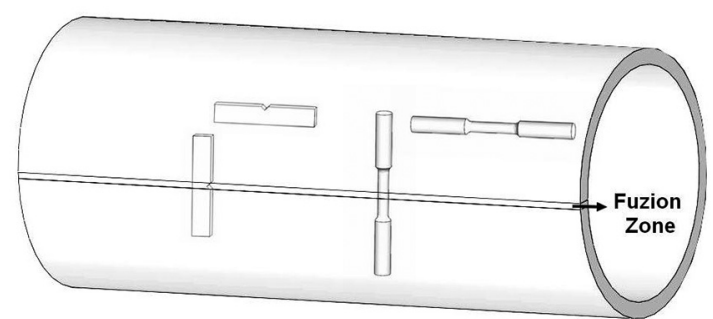

Figure 1: Location of tensile and CVN impact specimens in API 5L X65 pipe.

\subsection{Residual stresses analysis}

Surface residual stress was analyzed by the X-ray diffraction technique, using the $\sin ^{2} \psi$ method. The parameters used are given in Table 3. The stress measurement was performed in the XStress3000 portable analyzer, with a collimator of $\varnothing 1.0 \mathrm{~mm},(30 \mathrm{kV}$ and $6.7 \mathrm{~mA})$. The software XTronic V1-0 Standard (stresstechgroup.com) was used to stress calculation.

Residual stresses were measured in all tensile and Charpy specimens, before and after the hydrogenation treatment, and immediately before the mechanical tests. The total time from the end of hydrogenation up to the beginning of mechanical test lasted less than five minutes. Stress measurements were carried out in the longitudinal
(L) and tangential ( $\mathrm{T}$ ) directions in relation to the main axis of the specimens (Figure 3). All mechanical tests performed after hydrogenation were performed ex-situ of the electrolyte at $22{ }^{\circ} \mathrm{C}$.

\subsection{Heat treatment}

The stress-relief heat treatment (HT) of the tensile and Charpy specimens was accomplished in a tubular furnace with argon gas controlled atmosphere, with heating rate of 15 ${ }^{\circ} \mathrm{C} / \mathrm{min}$, to the temperature of $650{ }^{\circ} \mathrm{C}$ (for about two hours) and subsequently cooling rate of $1.5^{\circ} \mathrm{C} / \mathrm{min}$.

\subsection{Pre-strain}

For the pre-straining condition (PS), pre-strain of the tensile specimens was carried out in a uniaxial tensile machine, with a displacement control that led to a residual plastic deformation of the steel in order to increase the strength of the material. For this purpose, a load of $6.142 \mathrm{kN}$ was applied to tensile specimens prior to mechanical testing, in order to produce the strain corresponding to $15 \%$ of elongation of the steel, in as-received condition.

\subsection{Mechanical tests}

Charpy impact tests and tensile tests were performed at room temperature according to ASTM A370-14 ${ }^{13}$. Tensile tests were carried out in uniaxial testing machine, by applying a strain rate $6.25 \times 10^{-3} \mathrm{~s}^{-1}$.

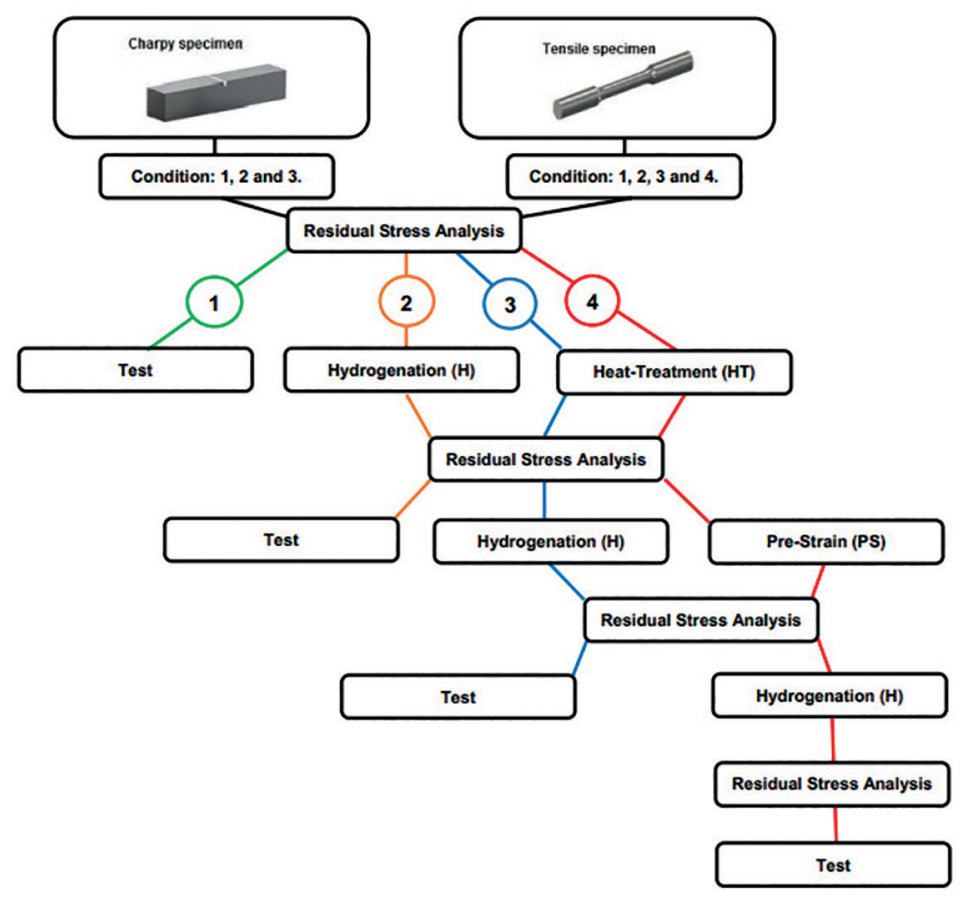

Figure 2: Description of the studied conditions and treatments. 
Table 3: Parameters used for the X-ray analysis.

\begin{tabular}{lcccc}
\hline Diffracting material & Diffracting plane $(h k l)$ & Radiation & Wavelength $(\AA)$ & Bragg angle 20 $\left(^{\circ}\right)$ \\
\hline $\mathrm{Fe}-\alpha$ & $(211)$ & $\mathrm{CrK} \alpha$ & $\lambda=2.29092$ & 156.41 \\
\hline
\end{tabular}

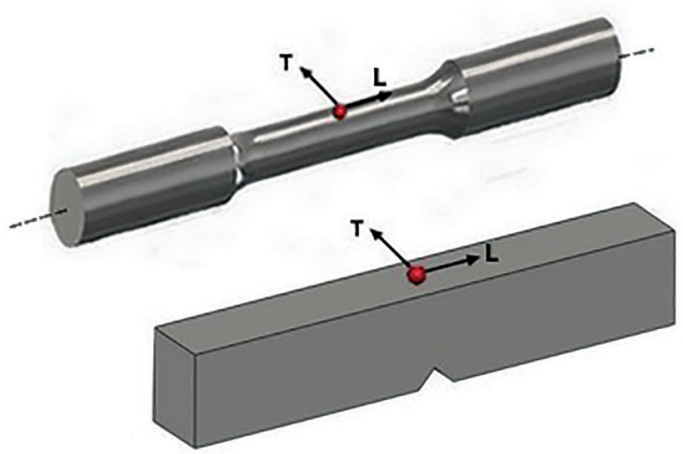

Figure 3: Residual stresses analysis directions.

\subsection{Microstructural characterization}

For the microstructural characterization of material, samples of the base metal (BM) and fusion zone (FZ) of the steel pipe were used. Samples for the optical microscopy were prepared with 100, 220, 400, 600 and 1200 grit sandpaper, polished with diamond paste of 1, 3 and $6 \mu \mathrm{m}$ and etched with $2 \%$ Nital solution ( $\mathrm{vol} / \mathrm{vol})$. The fracture surfaces of the Charpy and tensile specimens were characterized by scanning electron microscopy (SEM).

\section{Results and Discussion}

\subsection{Microstructural analysis}

Microstructural analysis by optical microscopy performed on the regions of the base metal and weld region revealed a ferritic-pearlitic microstructure. The heat affected zone (HAZ) and the fusion zone (FZ) of the welded joint exhibited the same microstructure of the base metal. The morphology of the grains are almost equiaxial, and the average grain size are base metal $(9.6 \mu \mathrm{m}), \mathrm{HAZ}(9.7 \mu \mathrm{m})$ and FZ $(10.0 \mu \mathrm{m})$. The grain sizes produced by the heat cycle of the ERW process during the pipe manufacturing are, on average, similar to base metal, as can be seen in Figure 4. The microstructure of the fusion zone presents a scattering of grain size, but even with this fact the average size is slightly higher than $\mathrm{BM}$ and HAZ.

\subsection{Hydrogenation of specimens}

The cathodic potential promoted the reduction of $\mathrm{H}^{+}$ion ${ }^{18}$. This electrochemical reduction generated $\mathrm{H}_{2}$ gas as well as monatomic hydrogen that is expected to diffuse through the steel crystalline lattice.
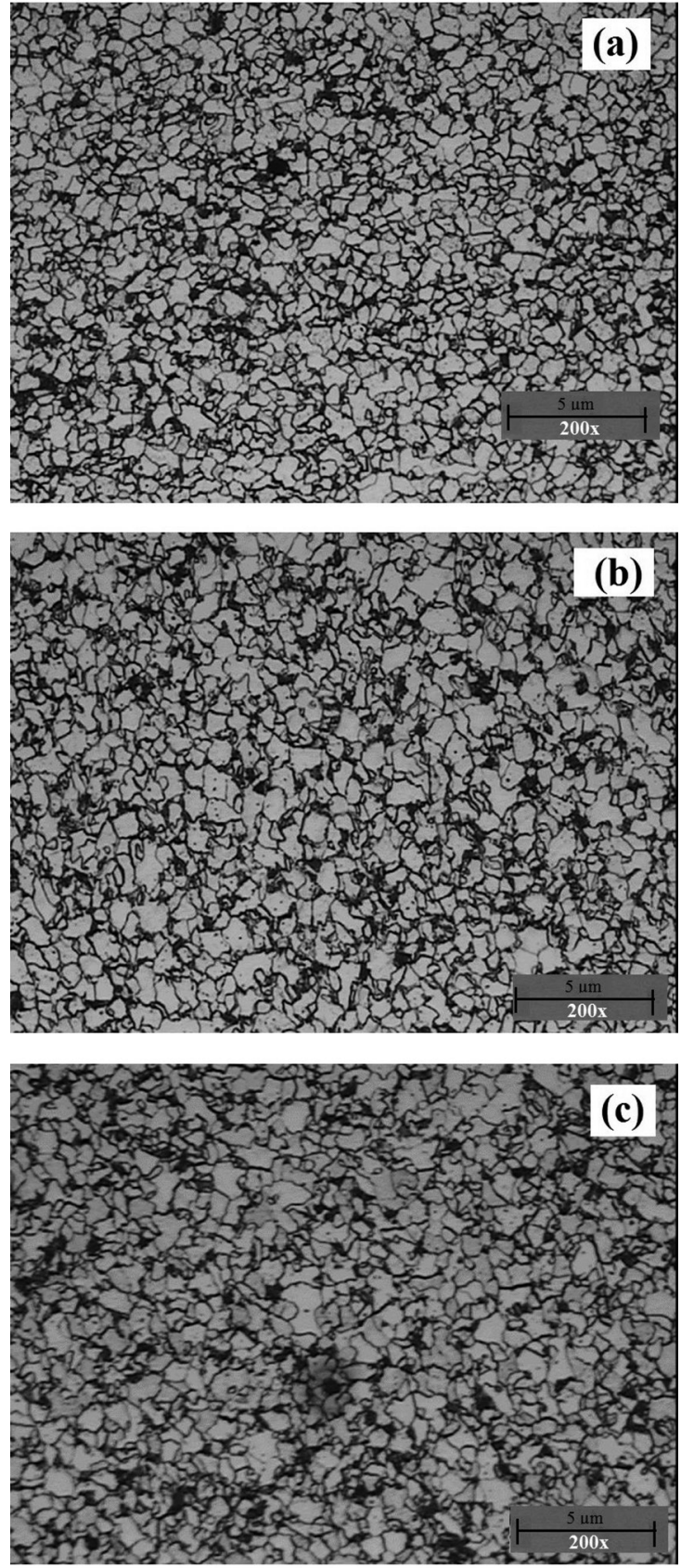

Figure 4: Microstructure of welded joint: (a) BM; (b) HAZ; (c) FZ.

\subsection{Residual stress analysis}

The results of residual stress analysis conducted on Charpy V-notch specimens (before the impact test) of BM and FZ (Condition 3, Figure 2) are shown in Figure 5. The as-received specimens have a compressive stress, except the longitudinal BM. Moreover, the longitudinal 

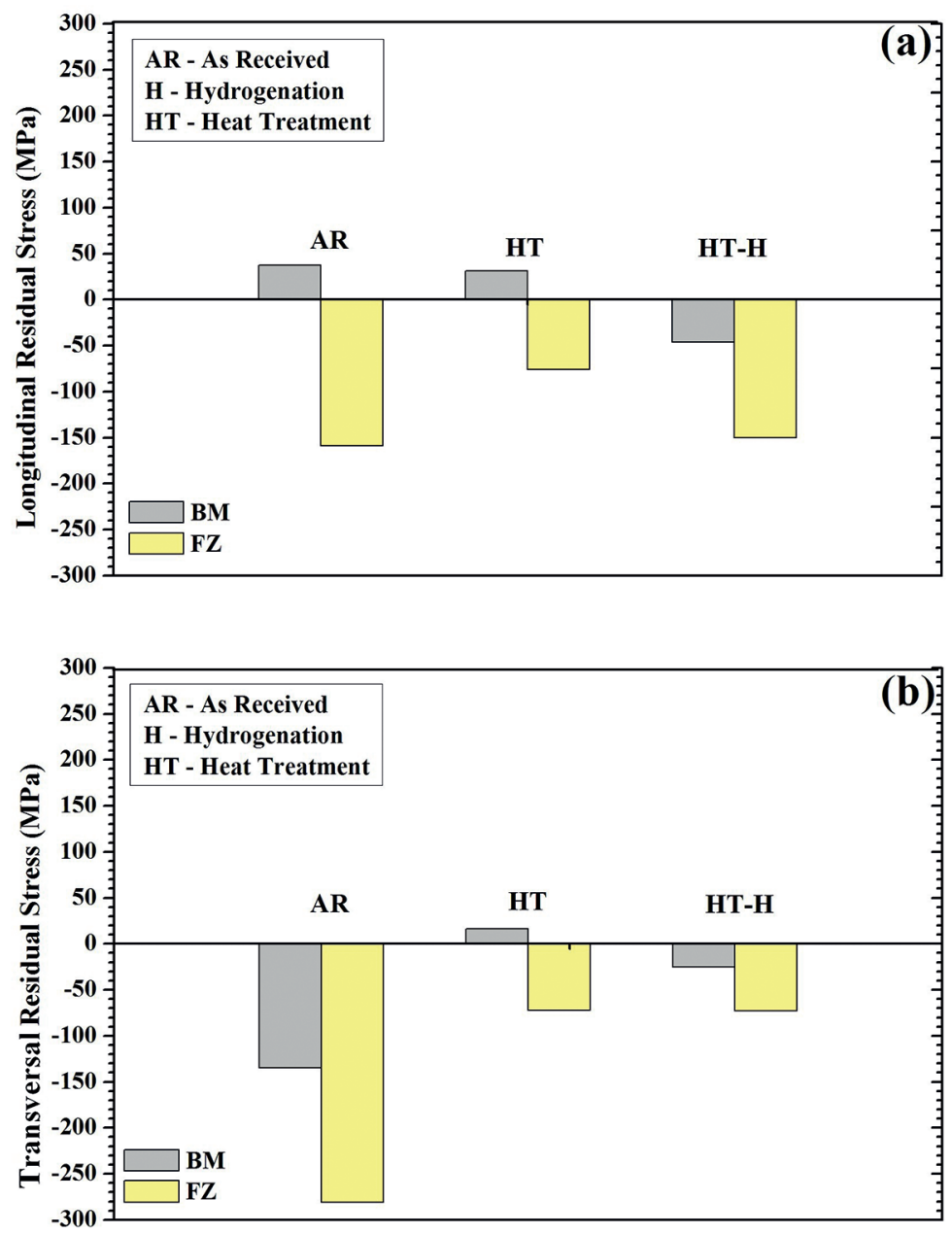

Figure 5: Residual stresses in Charpy specimens of BM and FZ in the Condition 3: (a) longitudinal residual stress; (b) transversal residual stress.

stress of BM specimen presents a small value, close to $40 \mathrm{MPa}$. The stress relief heat treatment (HT), applied to as-received materials, reduced the magnitude of compressive residual stresses generated in the specimens obtained by a machining process in both longitudinal and transversal directions.

The hydrogenation of HT specimens reversed the tensile residual stress of base metal (BM) and slightly increased the magnitude of the compressive residual stresses of FZ in the longitudinal direction, as shown in Figure 5a.

Residual stress analysis performed on the uniaxial round tensile test specimens of BM and FZ materials in the longitudinal (L) direction (to the sample axis), Condition 4, is shown in Figure 6. The as-received materials present compressive stress, except the FZ at tangential direction. When the pre-straining load (PS) was applied to specimens, the longitudinal residual stresses of the BM material became tensile, but its magnitude is relatively small. The compressive stress of FZ did not turn tensile even with pre-straining and hydrogenation. Furthermore, after the hydrogenation, the magnitude of the residual stresses in both materials increased and became more compressive in the FZ specimens and more tensile in the base metal specimens (Figure 6a).

In the tangential $(\mathrm{T})$ direction (in respect to the round sample axis) after pre-straining residual stresses became more compressive. Likewise, the hydrogenation process reversed residual stresses in the $\mathrm{FZ}$ condition, that became tensile $(150 \mathrm{MPa})$ while increased the magnitude of the compressive residual stresses of BM specimens, as shown in Figure 5b.

The changes in magnitude and nature of the residual stresses caused by hydrogen can be explained by the literature $^{19,20,21}$, because the trapping of monatomic hydrogen in the inclusions, defects or imperfections of the crystalline lattice of the steel can promote localized plastic deformation, contributing to the HELP mechanism. 

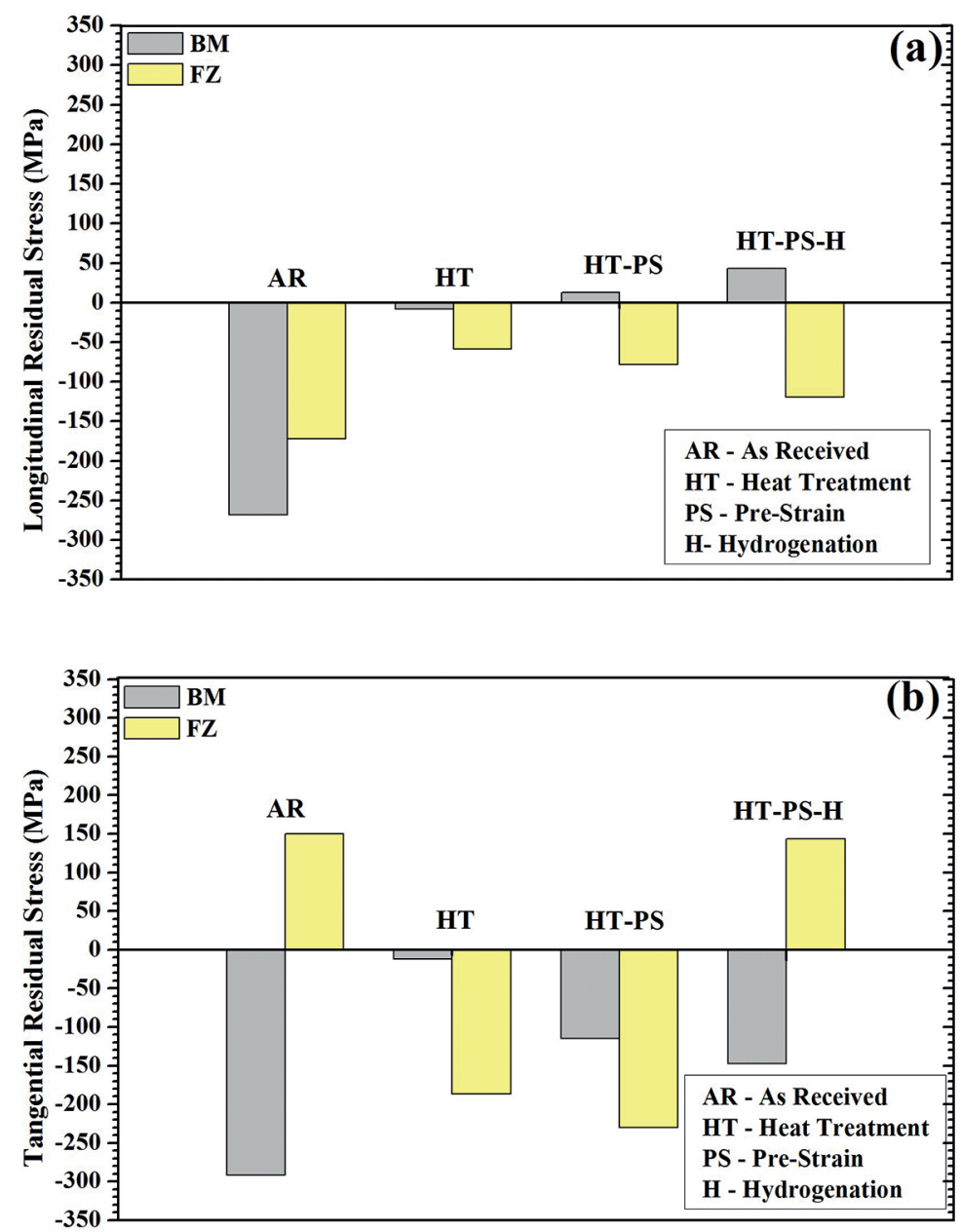

Figure 6: Longitudinal (a) and tangential (b) residual stresses in tensile pre-straining (PS) specimens of the BM material with stress relief heat treatment (HT).

These plastic deformations cause the disarray of the crystal lattice and/or deformation in the crystallographic planes, and can provoke changes in residual stress levels, favoring the process of nucleation and propagation of cracks, and consequently the embrittlement of steel ${ }^{19}$. Moreover, the steel microstructure hardening may have triggered the interaction between dislocations and residual stress fields of existing defects in the crystal lattice, facilitating the accumulation of the monatomic hydrogen and the $\mathrm{H}_{2}$ gas generation in these defects ${ }^{20}$. The increased internal pressure in these defects produced by the $\mathrm{H}_{2}$ gas can lead to increased localized plastic deformation, and consequently may change the magnitude and nature of residual stresses in these regions ${ }^{6}$.

\subsection{Effect of hydrogenation on mechanical properties}

The hydrogenation affected differently the mechanical properties of Charpy absorbed energy, depending on the microstructure. The BM specimens were virtually not affected by hydrogenation. On the other hand, the absorbed energy decreased after the hydrogenation for FZ specimens, as seen in Figure 7. Even the heat treatment was not sufficient to increase the toughness. The small difference between the absorbed energies of metal base is within the experimental error of Charpy test. The fusion zone seems more sensible to hydrogenation and the embrittlement is maintained even after the heat treatment (HT) of the samples. Probably, these results (Figure 7) can be justified by microstructural changes in the FZ metal due to thermal cycle of welding. This effect may be explained by the more heterogenous grain size of the steel microstructure with respect to the base metal. Microstructures with small grains have more grain boundary areas compared to coarse ones, which may be an important factor for the accumulation of monatomic hydrogen in the interfaces ${ }^{22}$. This high specific area would be an important factor for the accumulation of monatomic hydrogen in the interfaces. However, FZ 


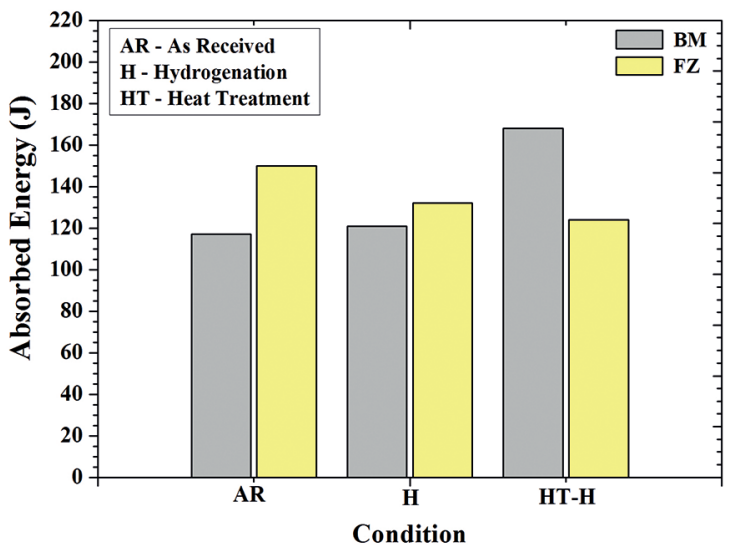

Figure 7: Absorbed energy of specimens subjected to different treatments.
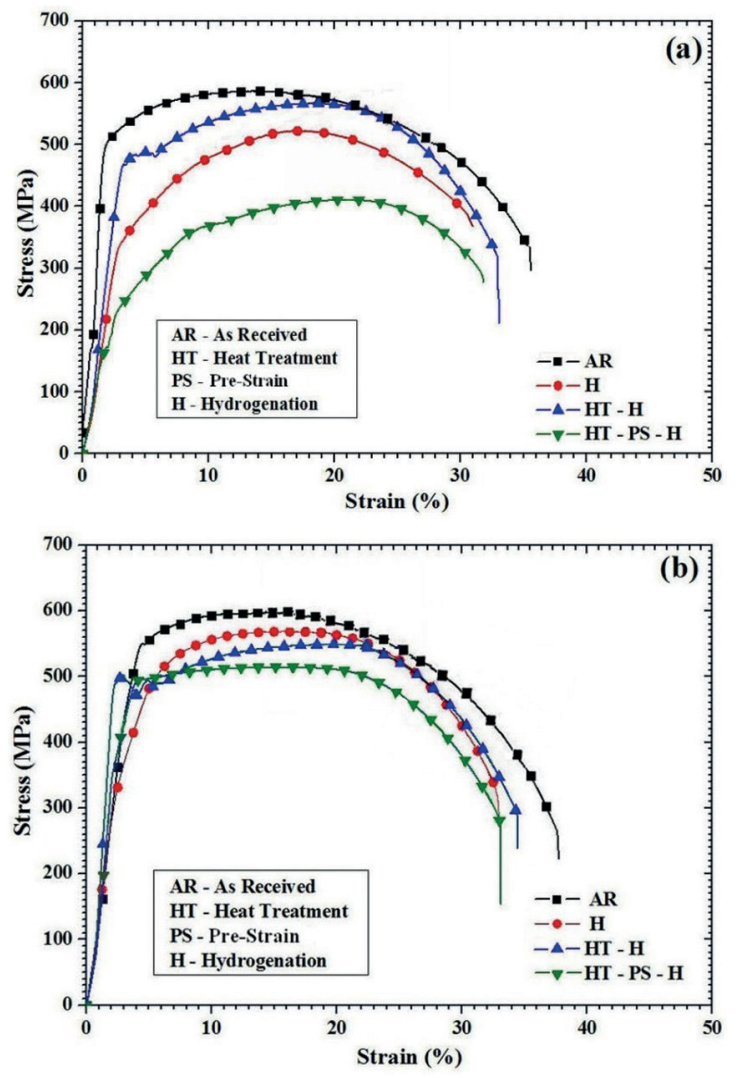

Figure 8: Stress-strain curves for the specimens subjected to different treatments. a) BM, b) FZ.

presents higher grain size than BM. Moreover, high grain size contributes to embrittlement at impact test. Thus, the results of absorbed energy are complex and probably can not be determined by just one property or treatment.

Figures $8 \mathrm{a}$ and $8 \mathrm{~b}$ present stress-strain curves for the $\mathrm{BM}$ and $\mathrm{FZ}$ round tensile specimens subjected to different treatments, respectively. Figure 8 a shows that the hydrogenation treatment $(\mathrm{H})$ decreased the yield strength and the strain to fracture of BM material. This steel embrittlement can be affected by the increase of the hydrogen concentration in the lattice defects during the diffusion process ${ }^{23}$. The specimens heat treated before hydrogenation give better results than the ones only hydrogenated. The heat treatment relieves the residual stress, consequently the hydrogen-stress field has less interaction. This fact is probably revealed in the stressstrain curve of Figure 8a. Nevertheless, specimens that after heat treatment were pre-strained and then hydrogenated had the lowest yield strength and strain to fracture. This shows that tensile properties can not be recovered by pre-straining, when followed by hydrogenation.

Fusion zone specimens (Figure 8b) exhibit no difference between the all hydrogenated conditions in the elastic region. However, strain hardening increased when heat treatment and pre-strain were applied prior to the hydrogenation. A reduction in fracture strain was observed for hydrogenated specimens, and the pre-strained condition presented the worst performance.

This embrittlement produced by hydrogenation in the steel microstructure can be explained by an increase in the number of dislocations caused by plastic deformation and the interaction between these defects and hydrogen. This effect may have facilitated the diffusion process and the increase in hydrogen concentration in these defects. Perhaps the plastic deformation produced around these defects favored nucleation and propagation of internal and surface cracks, which contributed to the embrittlement of steel. This behavior is consistent with the literature, since many authors have reported the influence of hydrogen in the reduction in ductility and strength of stee ${ }^{24-27}$.

\subsection{SEM fracture surfaces analysis}

Figure 9 shows the SEM micrographs of the fracture surfaces of the base metal (BM) test specimens, in asreceived (AR) condition. The specimens were broken down by Charpy toughness tests and exhibit microvoids in the fracture surface, indicating the ductile fracture morphology. The analysis of hydrogenated $(\mathrm{H})$ specimens showed mixed areas, with a prevalence of microvoids and rough surfaces, ductile fracture morphology; there was evidence of localized embrittlement caused by hydrogen, with the presence of quasi-cleavage regions.

The fracture surface analysis of the fusion zone hydrogenated (FZ-H) specimens, ruptured during the Charpy test, revealed a prevalence of quasi-cleavage regions, as shown in Figure 10. An increase of monatomic hydrogen concentration can create brittle regions around crystalline lattice defects causing localized plastic deformation, which may have contributed to the steel embrittlement ${ }^{7}: 19$. 

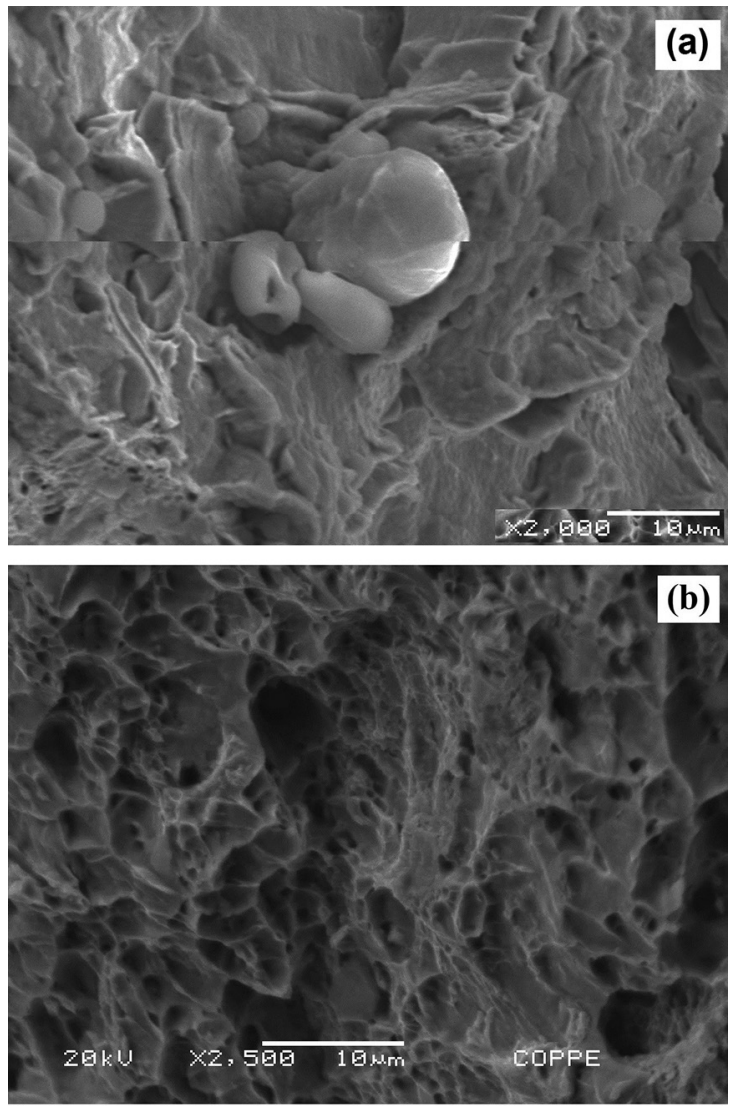

Figure 9: SEM of fracture surface after Charpy tests of base metal: (a) as-received, (b) hydrogenated.

The micrographs of the base metal HT-specimens, ruptured in Charpy tests, showed fracture surfaces containing regions mixed with the presence of roughness and microvoids. This is a ductile fracture mode characteristic of quasi-cleavage regions, as seen in Figure 11.

Figure 12 shows the micrograph analysis of the fracture surface of the BM specimens, in the HT-H condition (Figure 12b), compared with the AR condition (Figure 12a), ruptured by a uniaxial tensile test. The micrograph of the hydrogenated fracture surface revealed the prevalence of regions with microvoids and fibrous appearance; and in some fracture surface regions with quasi-cleavage aspects. This behavior is likely caused by an increase of hydrogen concentration in the crystal lattice defects that may have reduced the steel ductility ${ }^{23}$.

\section{Conclusions}

The results obtained in this study allow the following conclusions to be made:

1) Hydrogenation caused changes in the magnitude or the nature of pre-existing residual stresses in the specimens for all tested conditions. The
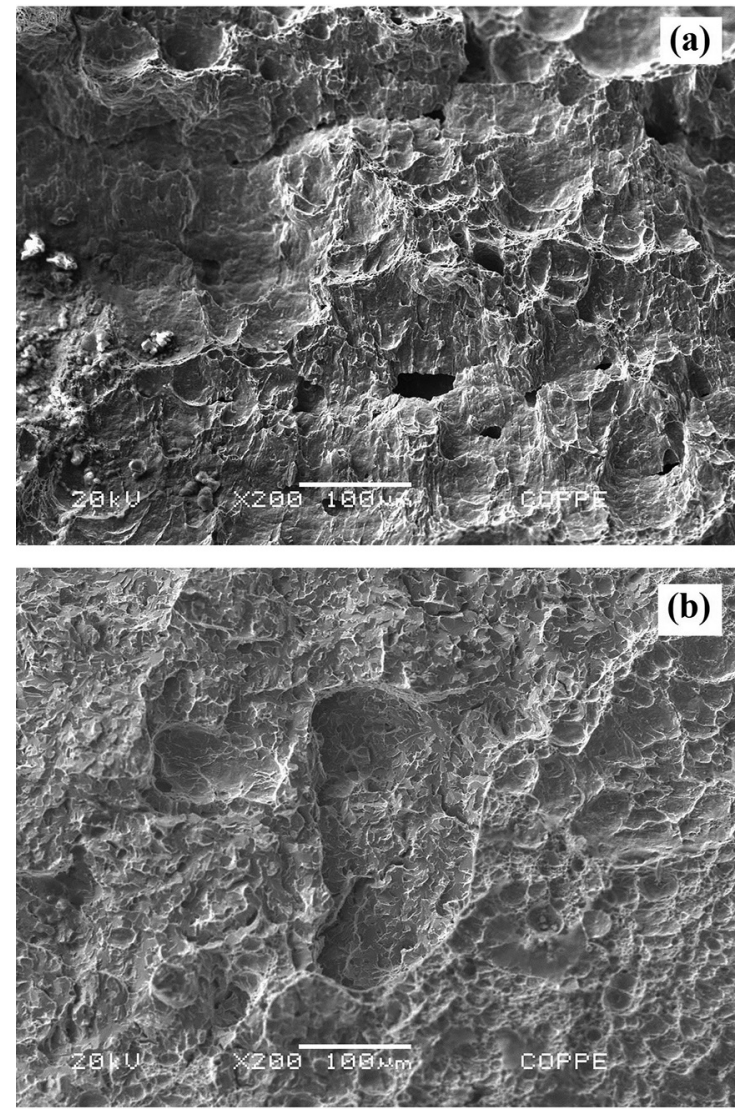

Figure 10: SEM of fracture surface after Charpy tests of the hydrogenated specimens of the fusion zone region: (a) rough aspects and microvoids; (b) quasi-cleavage regions.

hydrogenation increased the magnitude of the longitudinal residual stress of base metal and fusion zone, without changing the tensile/compressive nature. On the other hand, the hydrogenation increased the intensity of the tangential stress of base metal, and changed from compressive to tensile stress the fusion zone material.

2) Hydrogenation affected the Charpy absorbed energy of fusion zone specimens. The hydrogenation reduced the absorbed energy, and even the heat treatment did not recover the previous energy of fusion zone.

3) The heat treatment $\left(2\right.$ hours at $\left.650{ }^{\circ} \mathrm{C}\right)$ did not reduce the embrittlement of fusion zone. However, the heat treatment increased the absorbed energy of base metal of API 5L X65.

4) Tensile properties of all specimens were not recovered by pre-straining, when followed by hydrogenation.

5) The scanning electron microscopy of the fracture surfaces of hydrogenated base metal specimens showed mixed regions, with the presence of fibrous surface and microvoids, typical ductile fracture morphology and quasi-cleavage regions. 

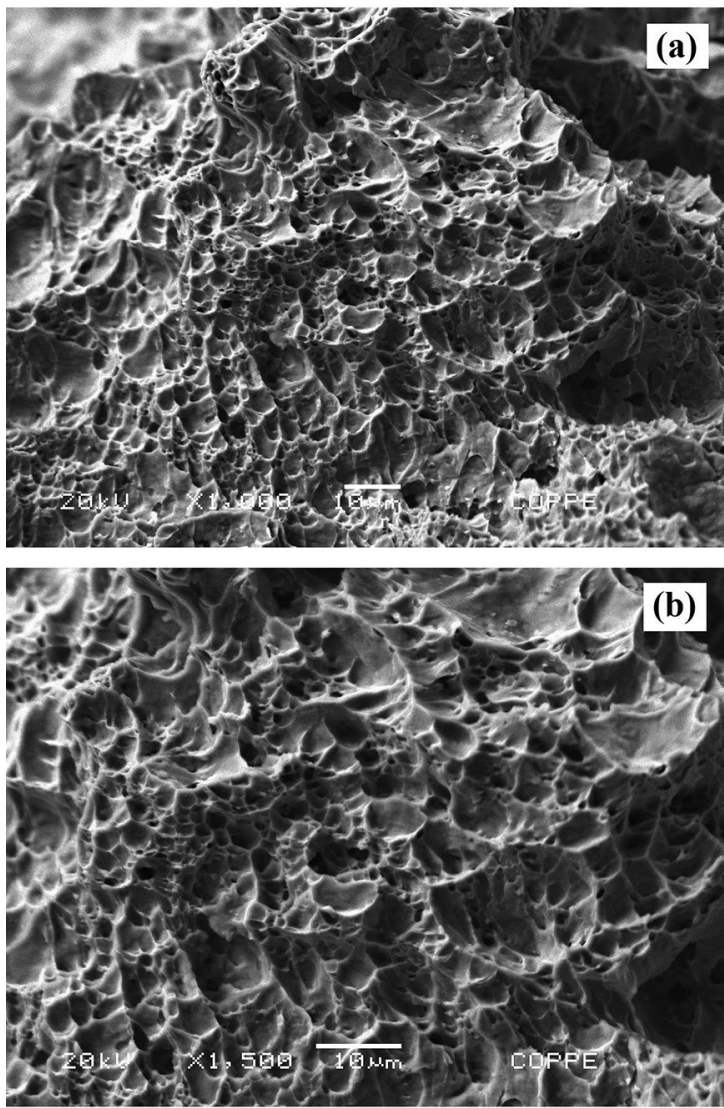

Figure 11: SEM of fracture surface after Charpy tests of hydrogenated $(\mathrm{H})$ specimens of the base metal with heat treatment $(\mathrm{HT})$ and hydrogenation $(\mathrm{H})$ : (a) rough aspects and microvoids; (b) small regions with quasi-cleavage aspects.

\section{Acknowledgements}

The authors would like to thank the Brazilian research agencies CNPq, CAPES and FAPERJ for the financial support.

\section{References}

1. Kang J, Wang C, Wang GD. Microstructural characteristics and impact fracture behavior of a high-strength low-alloy steel treated by intercritical heat treatment. Materials Science and Engineering: A. 2012;553:96-104

2. Godefroid LB, Cândido LC, Toffolo RVB, Barbosa LHS. Microstructure and mechanical properties of two API steels for iron ore pipelines. Materials Research. 2014;17(Suppl. 1):114-120.

3. Hong HU, Lee JB, Jin Choi HJ. Improvement of resistance to hydrogen induced cracking in electric resistance welded pipes fabricated with slit coils. Metals and Materials International. 2009;15(1):133-139.

4. Kim CM, Kim, JK. The effect of heat input on the defect phases in high frequency electric resistance welding. Metals and Materials International. 2009;15(1):141-148.
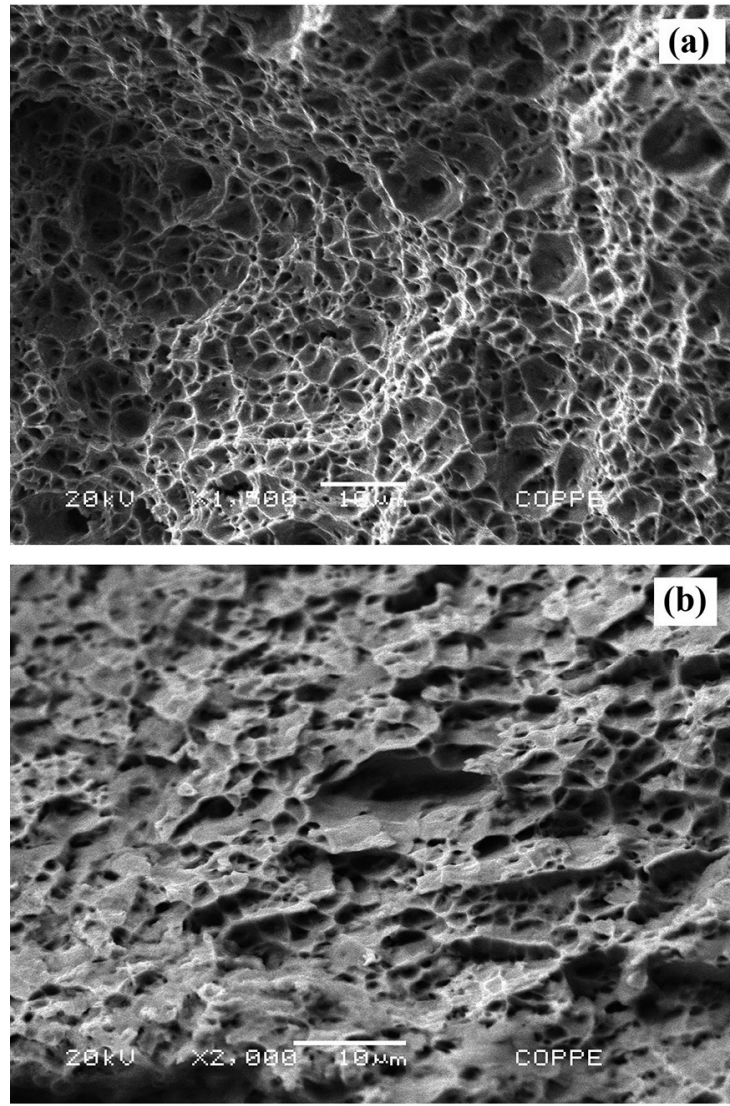

Figure 12: SEM of fracture surface after uniaxial tensile tes specimens of the base metal (BM): a) as received (AR), b) hydrogenated after heat treatment $(\mathrm{H}-\mathrm{HT})$.

5. Turski M, Francis JA, Hurrell PR, Bate SK, Hiller S, Withers PJ. Effects of stop-start features on residual stresses in a multipass austenitic stainless steel weld. International Journal of Pressure Vessels and Piping. 2012;89:9-18.

6. Wu T, Yan M, Zeng D, Xu J, Sun C, Yu C, et al. Hydrogen permeation of X80 steel with superficial stress in the presence of sulfate-reducing bacteria. Corrosion Science. 2015;91:86-94

7. Wang R. Effects of hydrogen on the fracture toughness of a X70 pipeline steel. Corrosion Science. 2009;51(12):2803-2810.

8. Dong CF, Li XG, Liu ZY, Zhang YR. Hydrogen-induced cracking and healing behaviour of X70 steel. Journal of Alloys and Compounds. 2009;484(1-2):966-972.

9. Beachem CD. A new model for the hydrogen-assisted cracking (hydrogen "embrittlement"). Metallurgical Transactions. 1972;3(2):441-455.

10. Troiano AR. The role of hydrogen and other interstitials in the mechanical behavior of metals. In: Workshops on Abstract State Machines - ASM; 1960;52:147-157.

11. Olden V, Alvaro A, Akselsen OM. Hydrogen diffusion and hydrogen influenced critical stress intensity in an API X70 pipeline steel welded joint - Experiments and FE simulations. International Journal of Hydrogen Energy. 2012;37(15):11474-11486. 
12. American Petroleum Institute. API Specification 5L. Forty-Fifth Edition. Washington: API Publishing Services; 2012.

13. ASTM A370-14. Standard test methods and definitions for mechanical testing of steel products. West Conshohocken: ASTM International; 2014.

14. Parkins RN, Blanchard WK Jr, Delanty BS. Transgranular stress corrosion cracking of high-pressure pipelines in contact with solutions of near neutral pH. Corrosion. 1994;50(5):394-408.

15. Sena RA, Bastos IN, Platt GM. Theoretical and experimental aspects of the corrosivity of simulated soil solutions. ISRN Chemical Engineering. 2012;2012:103715.

16. Bueno AHS, Moreira ED, Gomes JACP. Evaluation of stress corrosion cracking and hydrogen embrittlement in an API grade steel. Engineering Failure Analysis. 2014;36:423-431.

17. Crank J. The mathematics of diffusion. New York: Oxford University Press; 1993.

18. Pourbaix M. Atlas of Electrochemical Equilibria in Aqueous Solutions. Houston: National Association of Corrosion Engineers; 1974.

19. Dabah E, Kannengiesser T, Eliezer D, Boellinghaus T. Hydrogen Interaction with Residual Stresses in Steel Studied by Synchrotron X-Ray Diffraction. Materials Science Forum. 2014;772:91-95.

20. Mouanga M, Berçot P, Takadoum J. Effect of residual stresses on hydrogen permeation in iron. Corrosion Science. 2010;52(6):2010-2014.
21. Toribio J, Lorenzo M, Vergara D, Kharin V. Effects of manufacturing-induced residual stresses and strains on hydrogen embrittlement of cold drawn steels. Procedia Engineering. 2011;10:3540-3545.

22. Ghosh KS, Mondal DK. Effect of grain size on mechanical electrochemical and hydrogen embrittlement behaviour of a micro-alloy steel. Materials Science and Engineering: A. 2013;559:693-705.

23. Hardie D, Charles EA, Lopez AH. Hydrogen embrittlement of high strength pipeline steels. Corrosion Science. 2006;48(12):4378-4385.

24. Fallahmohammadi E, Bolzoni FM, Fumagalli G, Re G, Benassi G, Lazzari, L. Hydrogen diffusion into three metallurgical microstructures of a Ce-Mn X65 and low alloy F22 sour service steel pipelines. International Journal of Hydrogen Energy. 2014;39:13300-13313.

25. Arafin MA, Szpunar JA. Effect of bainitic microstructure on the susceptibility of pipeline steels to hydrogen induced cracking. Materials Science and Engineering: A. 2011;528(15):4927-4940.

26. Zhu Y, Li L, Wang C. Effects of tensile stresses on the oscillatory electrodissolution of $\mathrm{X} 70$ carbon steel in sulfuric acid solution. Corrosion Science. 2015;94:445-451.

27. Lee YH, Lee HM, Kim Y, Hahm SH. Mechanical degradation of API X65 pipeline steel by exposure to hydrogen gas. Metals and Materials International. 2011;17(3):389-395. 